\title{
EDITORIAL
}

\section{Arthritis: where are the T cells?}

\author{
Thomas Kamradt* and Oliver Frey \\ See related research by Angyal et al., http://arthritis-research.com/content/12/2/R44
}

\begin{abstract}
T-helper (Th) lymphocytes contribute to arthritis pathogenesis by helping B cells to produce antibodies, by producing cytokines that activate effector cells involved in the destruction of cartilage and bone, and by contributing to osteoclast differentiation. There are murine models of arthritis, most notably collagenand proteoglycan-induced arthritis, in which arthritis depends on T-cell recognition of antigens that are expressed in the joints. In spite of this, we still do not know the antigens recognised by arthritogenic Th cells in humans. Moreover, current evidence for Th cells exerting arthritogenic effector functions within the joints is only indirect.
\end{abstract}

In a paper in the previous issue of Arthritis Research and Therapy Angyal and colleagues [1] ask the fundamental question of how and where $\mathrm{T}$ cells contribute to arthritis pathogenesis. That $\mathrm{T}$ cells do contribute to arthritis pathogenesis is widely accepted: HLA-DRB1 is the bestestablished genetic locus influencing rheumatoid arthritis (RA); and other genetic risk factors, including PTPN22, are also relevant for T-cell function [2]. Abatacept, which blocks T-helper (Th) cell co-stimulation, is an effective treatment for RA patients [3]. Nonetheless, the specificity of pathogenic $T$ cells in RA remains unknown. Increasing evidence suggests that recognition of systemically expressed antigens by $\mathrm{T}$ cells can induce arthritis. Systemic autoimmune responses towards glucose-6-phosphate isomerase [4,5], fibrinogen [6], or transgenically expressed hemagglutinin [7] induce arthritis in mice. Moreover, systemic alterations that impact on T-cell reactivity result in arthritis. The so-called SKG mice and gp130 mutant mice spontaneously develop chronic joint inflammation [8]. In both models particular arthritogenic autoantigens have not been identified. Instead, $\mathrm{T}$ cell receptor signaling is altered in SKG mice, resulting in a broad repertoire of

${ }^{*}$ Correspondence: immunologie@mti.uni-jena.de

Institut für Immunologie, Universitätsklinikum Jena, 07740 Jena, Germany low-affinity autoreactive T cells. Autoimmunity towards systemically expressed antigens might well be relevant in human arthritis. Adaptive immune responses to citrullinated peptides are a hallmark of RA and the origin of the recognized citrullinated peptides is not restricted to joint-specific antigens [2]. Taken together, mounting evidence puts into question the notion that arthritogenic antigens must be joint-specific.

It is against this background that Angyal and colleagues [1] asked where the pathogenic $\mathrm{T}$ cells in arthritis exert effector functions. After immunizing with proteoglycan, they obtained spleen cells from arthritic mice, labeled the $T$ cells with a fluorescent dye, and transferred the labeled $\mathrm{T}$ cells together with the antigen-presenting cells into SCID (severe combined immunodeficient) mice. Next, they used multi-photon microscopy to identify the transferred $\mathrm{T}$ cells in the recipients' ankle joint and lymph nodes. Whereas $\mathrm{T}$ cells were demonstrable in lymph nodes for at least 12 days after transfer, very few were detectable in the joint.

Where, then, do the pathogenic T cells act? To address this, the authors transferred either whole spleen cells, or spleen cells depleted of $\mathrm{T}$ lymphocytes into recipient mice. One group of mice receiving whole spleen cells was treated with FTY720, an agonist of the phospholipid sphingosine 1 phosphate, which sequesters lymphocytes in lymph nodes and peripheral tissues. Arthritis developed in the recipients of whole spleen cells regardless of whether the recipients received FTY720 or not. The number of $\mathrm{T}$ cells in the secondary lymphatic organs and the titers of IgG1 antibodies against proteoglycan were similar in the FTY720-treated and control mice. In contrast, the recipients of T-cell-depleted splenocytes were protected from arthritis and lacked IgG1 antibodies against proteoglycan. Angyal and colleagues conclude that the $\mathrm{T}$ lymphocytes' function in proteoglycaninduced arthritis is to provide help for the production of pathogenic antibodies, mirroring earlier findings in the $\mathrm{K} / \mathrm{BxN}$ arthritis model [4].

Although interesting and provocative, these data do not rule out the possibility that $\mathrm{T}$ cells in the joint are required for development of proteoglycan-induced arthritis. Few $\mathrm{T}$ cells were detectable in the joints 12 days after the adoptive transfer of spleen cells. However, at 
this time point the prevalence of arthritis is very low and clinical signs of arthritis mild. Could it be that pathogenic $\mathrm{T}$ cells egress into the joint later in the course of disease, that is, immediately before the onset of arthritis? This was shown in earlier work in the collagen-induced arthritis model [9]. Treating recipient mice with FTY720 after adoptive cell transfer also has its pitfalls: FTY720 prevents the exit of lymphocytes from the lymph nodes as well as their exit from the target tissue [10]. Thus, effector/memory cells adoptively transferred intravenously can move directly into the joint before being trapped in the lymph nodes by FTY720. In fact, while FTY720 treatment reduced the numbers of $\mathrm{T}$ cells in the joint, this reduction did not reach statistical significance [1]. Thus, it may be too early to dismiss a role for local $\mathrm{T}$ cell action in arthritis.

On the other hand, current evidence that pathogenic $T$ cells need to exert effector functions within the joints is indirect. Synovial tissue from RA patients contains $\mathrm{T}$ cells, B cells and dendritic cells and sometimes also lymphoid follicles with germinal-center-like structures [2]. T cells from synovial tissue can produce cytokines such as IL-17, which are relevant for arthritis pathogenesis. It is unclear, however, if $\mathrm{T}$ cells recognize antigen within the joint. $\mathrm{T}$ cells obtained from synovial tissue have a peculiar phenotype compatible with their activation by cytokines rather than antigen recognition. Whatever triggers the local activation of $\mathrm{T}$ cells within the joints, synovial fibroblasts are exquisitely sensitive for IL-17 and other T-cell-derived cytokines [2]. Angyal and colleagues have demonstrated in a series of elegant experiments that we still do not know where $\mathrm{T}$ cells exert their arthritogenic functions. This topic clearly merits further investigations.

\section{Abbreviations}

$\mathrm{IL}$ = interleukin; $\mathrm{RA}=$ rheumatoid arthritis; $\mathrm{Th}=\mathrm{T}$ helper.
Competing interests

The authors declare that they have no competing interests.

Published: 3 June 2010

References

1. Angyal A, Egelston C, Kobezda T, Olasz K, Laszlo A, Glant TT, Mikecz K: Development of proteoglycan-induced arthritis depends on $T$ cellsupported autoantibody production, but does not involve significant influx of T cells into the joints. Arthritis Res Ther 2010, 12:R44.

2. Goronzy JJ, Weyand CM: Developments in the scientific understanding of rheumatoid arthritis. Arthritis Res Ther 2009, 11:249.

3. Maxwell L, Singh JA: Abatacept for rheumatoid arthritis. Cochrane Database Syst Rev 2009:CD007277.

4. Matsumoto I, Staub A, Benoist C, Mathis D: Arthritis provoked by linked T and B cell recognition of a glycolytic enzyme. Science 1999, 286:1732-1735.

5. Schubert D, Maier B, Morawietz L, Krenn V, Kamradt T: Immunization with glucose-6-phosphate isomerase induces T-cell dependent peripheral polyarthritis in genetically unaltered mice. J Immunol 2004, 172:4503-4509.

6. Hill JA, Bell DA, Brintnell W, Yue D, Wehrli B, Jevnikar AM, Lee DM, Hueber W, Robinson WH, Cairns E: Arthritis induced by posttranslationally modified (citrullinated) fibrinogen in DR4-IE transgenic mice. J Exp Med 2008, 205:967-979

7. Rankin AL, Reed AJ, Oh S, Cozzo Picca C, Guay HM, Larkin J 3rd, Panarey L, Aitken MK, Koeberlein B, Lipsky PE, Tomaszewski JE, Naji A, Caton AJ: CD4+ $T$ cells recognizing a single self-peptide expressed by APCs induce spontaneous autoimmune arthritis. J Immunol 2008, 180:833-841.

8. Sakaguchi S, Sakaguchi N: Animal models of arthritis caused by systemic alteration of the immune system. Curr Opin Immunol 2005, 17:589-594.

9. Svendsen P, Andersen CB, Willcox N, Coyle AJ, Holmdahl R, Kamradt T, Fugger $\mathrm{L}$ : Tracking of proinflammatory collagen-specific $T$ cells in early and late collagen-induced arthritis in humanized mice. J Immunol 2004, 173:7037-7045.

10. Ledgerwood LG, Lal G, Zhang N, Garin A, Esses SJ, Ginhoux F, Merad M, Peche H, Lira SA, Ding Y, Yang Y, He X, Schuchman EH, Allende ML, Ochando JC, Bromberg JS: The sphingosine 1-phosphate receptor 1 causes tissue retention by inhibiting the entry of peripheral tissue T lymphocytes into afferent lymphatics. Nat Immunol 2008, 9:42-53.

doi:10.1186/ar3008

Cite this article as: Kamradt T, Frey O: Arthritis: where are the T cells? Arthritis Research \& Therapy 2010, 12:122. 